\title{
Socio-Economic Impact of Insurgency and Enterprises Engaged in by Internally Displaced Persons in Borno State, Nigeria: Implications for Counselling
}

\author{
Ngohi Bukar Umar ${ }^{1}$, Ibrahim Dahiru Idriss ${ }^{2}$, Taofeek Muhammed Thani ${ }^{3}$, Aliyu Idris ${ }^{4}$ \\ Department of General Studies, Mohammed Goni College of Legal and Islamic Studies, \\ Maiduguri, Borno State Nigeria ${ }^{1}$, Department of Primary Education, Federal College of \\ Education Potiskum, Yobe State Nigeria ${ }^{2}$, Research and Development Unit, Adni Islamic \\ School, Ampang Malaysia ${ }^{3}$, Department of Political Science, Federal University Gashua, \\ Yobe State Nigeria ${ }^{4}$ \\ \{ngohiumar@gmail.com¹, ibrahimdahiruidriss@gmil.com², kolapojunior@gmail.com³, \\ aliyudrss@gmail.com ${ }^{4}$ \}
}

\begin{abstract}
The study was a survey that determined the socio-economic impact of insurgency and enterprises engaged in by IDPs in Borno State, Nigeria. Population of the study comprised of 64,437 IDPs. However, 6000 were sampled from 4 Camps. Cluster and Multistage sampling techniques were adopted in picking sample. Researchers' instrument tagged IDPIS was used to elicit data for the study which was divided into three parts. Part "A" sought information on bio-data of the respondents; Part "B" elicited data on socioeconomic impacts while Part " $\mathrm{C}$ " solicited information on enterprises engaged in. Face and content validity of the instrument was .84 and reliability coefficient of .98 was obtained. Descriptive and inferential statistics were used for data analysis. Findings of the study revealed destructions of private and public structures while some of the enterprises engaged in by IDPs include: Tailoring/embroidery and commercial transportation. Based on the findings, some counselling implications and recommendations were made.
\end{abstract}

Keywords: Insurgency, Socio-economic impact, Implications for Counselling

\section{Introduction}

The number of lives lost, private and public properties destroyed by the insurgents between 2009 and 2019 using locally made and sophisticated weapons is worse than natural disasters of the century put together and the waves will remain immortal in the retention of the survivors. [1] reported that Borno on the international front is the only State in Nigeria bordered by three countries of Cameroun, Niger and Tchad. These countries constitute major trading partners to the State in particular and Nigeria in general. Substantial amount of the State's livestock requirement comes from Cameroun and Tchad. Borno State also provides ready market for her neighboring countries in terms of agricultural and industrial products. Thus, there was a buoyant cross-border trade between the State and her international neighbors prior to the advent of the insurgents. On the local front, the State is bordered by three States namely Adamawa, Gombe and Yobe. Internally, Borno State is composed of 27 
local government areas and each has its spacio-temporal market day arrangement with dissimilar traded products [2].

Trade between Borno State and the international community predate Nigeria's independence and it was enhanced by Economic Communities of West African States (ECOWAS) protocol which permits free flow of goods and services within and between member nations. The items of trade between Borno State and the neighboring international community basically include agricultural products such as millet, maize, sorghum, rice, cotton, beans, groundnuts, soya-beans, sesame, salt, potassium and onion. Others are hides and skin, dried and smoke fish as well as livestock (cattle, sheep and goats). Industrial products include textiles, carpets and rugs, detergents, iron and plastic buckets, dishes, slippers, containers, kettles and cooking utensils of different types, shapes and designs, cooking oil, washing/laundry and toilet soaps, Maggi, toilet tissues, scents, caps, beverages, furniture and building materials in addition to great potentials in tourism and mineral resources.[3] Crossborder trade activities between Borno State and Cameroun, Niger and Tchad have been flourishing on a wider scale right from the time immemorial not until the monster of insurgency altered its course [2,4].

According to, the incursion of Boko Haram into the body polity of northeastern Nigeria with particular reference to Borno State led to monumental loss of economic lives and properties [5]. The losses incurred by the State between 2009 and mid 2014 include 5,257 livestock (cattle, sheep and goats) killed, many major and spacio-temporal markets (in Konduga, Kawuri, Bama, Rumirgo, Damboa and Alagarno) and over 94 shops were burnt. All herds belonging to the villagers in Kawuri were carted away by the invaders. Tashan Baga fish market in Maiduguri was burnt with over 280 shops fully loaded with grains. The average capacity of each grain shop is 1800-6000 bags. Dried and smoked fish of over 12 billion naira were also burnt. Between 2008 and 2014, well over 820,940 tonnes of grains from Gamboru market and over 681,600 tonnes of grains from Baga market were burnt by the insurgents amounting to trillions of naira.

The public relations unit of the Nigeria Customs Service (2019), revealed that Borno/Yobe area command with its operational headquarters in Maiduguri generates between 25 million to 30 million naira only on weekly bases as revenue through its 15 border posts linking Cameroun, Niger and Tchad from the import-export of hide and skin, gum Arabic, dry fish, sesame seeds, groundnut cake, livestock, potassium, ginger, rubber, gallstone, cement, biscuits and garlic apart from serving as transit route for goods destined to neighboring countries prior to the insurgency havoc. Due to the challenges posed by the mayhem of the insurgents coupled with the executive order banning import-export of dry fish and livestock as the principal sources of revenue, the area command generates as low as 3 million to 4 million naira only peer week through Gamboru, Banki and Geidam borders that are operational on skeletal bases. [6] expressed that apart from the humanitarian cost or monumental loss of over 2 million lives comprising of males, females, children, destitute and the aged living some thousands as widows, widowers and orphans, the economic cost of the insurgency in Borno as the epicenter of Boko Haram include the burning of 287 markets, over 2,579 shops were burnt, 3,239,102 public and well over 9,135,123 private structures were reduced to ashes, more than 2,731 worship centers were burnt, 3,118,465 estimated number of livestock were killed and others stolen. Over 1,118,221 cattle, sheep and goats were hijacked en-route to Aba, Lagos and Onitsha, about 9,743 cars, 97,582 motor cycles and 2,975 tri-cycles were burnt [7] stressed that the tasty dried and smoked fish popularly known as the "Baga dried fish" from Borno State that weekly produce no less than 300 truckloads that disappeared from market following the insurgency is a thoughtful economic setback 
The internally displaced persons are faced with a range of socio-economic challenges despite the elaborate empowerment measures/policies designed by government at all levels such as the Small Scale Industries (SSIs), Small and Medium Enterprise (SME), Nigerian Enterprise Promotion Decree (NEPD), Small Business Congress (SBC), National Directorate of Employment (NDE), Centre of Management Development (CMD), Nigerian Association of Small Scale Industries (NASSI), Nigerian Bank for Commerce and Industry (NBCI), Nigerian Agricultural and Cooperative Bank (NACB), Nigerian Agricultural and Development Bank (NADB), Nigerian Industrial Development Bank (NIDB), Small Scale Industry Credit Scheme (SSICS), National Association of Women in Business (NAWB), National Animal Production Research Scheme (NAPRS), National Economic Reconstruction Fund (NERFUND), the Cassava Production Scheme (CPS) and the Bank of Industry (BOI) and the effort made by the organized private sector towards providing employment, numerous youths are roaming the streets unemployed [8].

Umezulike stressed that problem of unemployment is obvious and government alone cannot continue to create employment for the teaming populace. Therefore, youths should begin to create private enterprise that would earn them a living. Entrepreneurship entails using ones' ability, knowledge, initiative and creativity to innovate or come up with something worth-while to do that one can hang on for a living [8]. According to Eyiyere an entrepreneur is a person who conceives of a business idea and organizes all other factors of production to achieve the objectives of maximizing profit [9]. Entrepreneur combines the functions of organizing, planning, funding, managing, taking major decisions, employing additional hands to work and bears the risk that could arise from the business enterprise [10]. However, [11] postulated that entrepreneurship is all about the willingness and ability of an individual or group to search for investment opportunities, source the funds, establish and run an enterprise/business successfully [11]. It is against this background that this study seeks to determine the socio-economic impacts of insurgency and the types of enterprises engaged in by internally displaced persons in Borno State, Nigeria with a view to proffer some counselling implications [12]. The study was designed to determine the following objectives:

a) Socio-economic impact of insurgency by gender in Borno State, Nigeria.

b) Enterprises engaged in by IDPs by gender in Borno State, Nigeria

c) If there exists gender difference on socio-economic impact of insurgency in Borno State

d) If there exists gender difference on enterprises engaged in by IDPs in Borno State, Nigeria

The following research questions piloted the study:

a) What is the socio-economic impact of insurgency by gender in Borno State, Nigeria?

b) What are the enterprises engaged in by IDPs by gender in Borno State, Nigeria?

The following null-hypotheses were tested for the study at 0.05 alpha level:

Hypotheses 1: There is no significant gender difference on the socio-economic impact of insurgency in Borno State, Nigeria

Hypotheses 2: There is no significant gender difference on the enterprises engaged in by IDPs in Borno State, Nigeria

\section{Review of Related Literature}

The concept of insurgency according to [1] refers to an active revolt or uprising waged by armed rebels (insurgents) against the constituted national, state and local authorities that ends 
up killing millions of innocent lives and destructions of private and public properties worth trillions of naira while [2], considered insurgency as violent rebellion organized by nonbelligerents against any recognized authority leading to bloodshed and loss of belongings. The internally displaced persons according to [1] are those people forcefully made to flee their ancestral homes for their dare lives and took refuge in their neighboring villages, the local government headquarters or come to the city center.

According to [13] women, young and the aged were the worst hit by the impromptu and inhuman activities of the insurgents. Apart from destruction of their residents, foodstuff and other valuables, hundreds and thousands of them were left as widows and orphans taking refuge in some dilapidated and uncompleted structures as well as markets stalls in various locations within Maiduguri Metropolis and Jere Local Government Area while some hundreds fled to the neighboring States of Adamawa and Yobe. [14], expressed that thousands of the innocent residents (women, young and the aged) especially in Abadam, Magumeri, Mafa, Gamboru-Ngala and Mobar fled to the neighboring countries of Tchad, Cameroun and Niger for their dare lives. They are often referred to as refugees as they are usually stranded and hung-on with relatives, close friends, under shade or in dilapidated structures within their boundaries surviving on assisted or relief materials from government agencies, philanthropists, non-governmental organizations and other highly spirited individuals [15], expressed that historically, from the first world war to the contemporary socio-political and religious violent killings, no less than 13.933 million people were killed in the Middle East and North Africa, 2.804 million people killed in Europe and North Asia, 10.762 million people killed in Sub-Saharan Africa, 2.879 million people killed in Asia and the Pacific and over 7.113 million people were killed in Americas. War, civil conflicts, political strife, boundary disputes, inter and intra communal clashes and gross human rights abuse characterized human evolution right from the time immemorial [6].

The Internally Displaced Persons (IDPs) were made to flee their homes as impromptu and found themselves under harsh economic conditions, in an attempt to get out of the predicaments, may venture into varying enterprises to keep mind and soul this is because according to [16] engaging in enterprises and any form of money making ventures reliefs one from the pains of economic deprivation, dispossessions, condemnation, isolations, depression, loneliness, resentment, feelings of shame and psycho-social disaffections. It is against this background that this study identified the enterprises engaged in by the IDPs in Borno State, Nigeria following the devastating activities of the insurgents and proffer some implications for counselling.

\section{Methodology}

The study adopted survey research design that determined the socio-economic impact of insurgency and enterprises engaged in by internally displaced persons in Borno State, Nigeria. The target population of the study comprised of all the 64,437 IDPs in Borno State, Nigeria. However, cluster and multistage random sampling techniques were used in picking 6000 IDPs from 4 government designated camps by the State Emergency Management Agency (SEMA) in Jere Local Government area and Maiduguri Metropolis housing IDPs from 10 local government areas across the State. [17] table for determining sample size of a given population was used in drawing sample for the study. Each camp was considered a cluster, the sampled camps were Arabic Teachers' College (ATC) Camp housing IDPs from Askira/Uba, Gwoza and Kukawa local governments, Federal Training Center (FTC) Camp housing IDPs from Bama and Konduga local governments, Mohammed Goni College of Legal 
and Islamic Studies (MOGCOLIS) Camp housing IDPs from Monguno and Ngala local governments and Government Girls' College (GGC) housing IDPs from Baga, Chibok and Damboa local governments. Volunteered respondents in each of the 4 clusters for the study were used. In the first stage, 4 out of the 9 government designated IDP camps were randomly selected, in the second stage, 10 out of the 27 local government areas covering the 3 senatorial districts were picked while in the third and stage, 1,500 IDPs from each cluster were randomly selected from the volunteered male and female respondents based on gender, age, highest educational qualification, local government area of origin, occupation and marital status.

Researchers' self-authored open ended Structured Interview Schedule (S.I.S) was used to elicit data for the study. The instrument was divided into 3 parts (A, B, \& C). Part "A" sought information on bio-data of the respondents such as age, gender, marital status, occupation, home town and highest educational qualification. Part "B" solicited information on the socioeconomic impact of the insurgency while Part " $\mathrm{C}$ " obtained data on the enterprises engaged in by IDPs in Borno State, Nigeria. Face and content validity of the instrument was .88 as determined by experts in the fields of Measurement and Evaluation and Counselling Psychology from the University of Maiduguri. Items in the instrument with less than $80 \%$ acceptance by the experts were removed. The experts' views were appropriately and adequately incorporated. Reliability of the instrument was established through pilot-testing among 150 IDPs in 3 camps outside the IDP Camps under study. The test-re-test method adopted using Cronbach alpha yield a reliability coefficient value of .96 which was considered suitable, adequate and adjudged appropriate for what the study purports to achieve. Copies of the instrument were administered by the researchers and 5 research assistants selected from amongst the camp officials at each of the sampled camps. Purpose of the study was explained to the IDPs and camp officials at each of the sampled cluster prior to the commencement of data collection and that participation was voluntary. Thereafter, the responses were collected on the spot which ensures $100 \%$ retrieval. The data collected from the subjects were analyzed using descriptive statistical techniques of frequency counts and percentages. The responses were further ranked to give a pictorial view of the respondents' rating of each item on the instrument while t-test statistical method was used in testing the null-hypotheses at 0.05 alpha level. Five objectives, three research questions and two null-hypotheses guided the study and the findings are presented in Tables 1-4.

\section{Results and Discussions}

Research Question 1: What is the socio-economic impact of insurgency by gender in Borno State, Nigeria?

Table 1. Socio-economic impacts of Insurgency by gender in Borno State, Nigeria.

\begin{tabular}{lcccc}
\hline \multirow{2}{*}{\multicolumn{1}{c}{ Socio-economic Impact }} & \multicolumn{2}{c}{ Male } & \multicolumn{2}{c}{ Female } \\
\cline { 2 - 5 } & Response & Rank & Response & Rank \\
\hline Destructions of Structures & $773(12.88)$ & $1^{\text {st }}$ & $689(11.48)$ & $1^{\text {st }}$ \\
Burnt Vehicles & $601(10.02)$ & $2^{\text {nd }}$ & $623(10.38)$ & $2^{\text {nd }}$ \\
Livestock Killed/Stolen & $559(9.32)$ & $3^{\text {rd }}$ & $509(8.48)$ & $3^{\text {rd }}$ \\
Farm Produce Burnt/Stolen & $397(6.62)$ & $4^{\text {th }}$ & $407(6.79)$ & $4^{\text {th }}$ \\
Truncates Movement of Goods and Services & $322(5.36)$ & $5^{\text {th }}$ & $383(6.38)$ & $5^{\text {th }}$ \\
Shortens Revenue Generation & $204(3.40)$ & $6^{\text {th }}$ & $238(3.97)$ & $6^{\text {th }}$ \\
Curtails Cross-Border Trade & $171(2.85)$ & $7^{\text {th }}$ & $124(2.07)$ & $7^{\text {th }}$ \\
\hline \multicolumn{1}{c}{ Total } & $\mathbf{3 , 0 2 7 ( 5 0 . 4 5 )}$ & & $\mathbf{2 9 7 3 ( 4 9 . 5 5 )}$ & \\
\hline
\end{tabular}

Note: All responses in parentheses are percentages of the raw scores. 
Table 1 indicated that destructions of private and public structures, burnt vehicles and livestock killed/stolen comprised the major socio-economic impact of insurgency in Borno State, Nigeria while truncates movement of goods and services, shortens revenue generation and curtails cross-border trade constituted the least socio-economic impact of insurgency for both male and female respondents in the study area. Research Question 2: What are the enterprises engaged in by IDPs by gender in Borno State, Nigeria?

Table 2. Enterprises engaged in by IDPs by Gender in Borno State, Nigeria.

\begin{tabular}{|c|c|c|c|c|}
\hline \multirow[b]{2}{*}{ Enterprises } & \multicolumn{2}{|c|}{ Male } & \multicolumn{2}{|c|}{ Female } \\
\hline & Response & Rank & Response & Rank \\
\hline Tailoring/embroidery & $222(3.70)$ & $1^{\text {st }}$ & $523(8.72)$ & $1^{\text {st }}$ \\
\hline Car and carpet wash & $164(2.73)$ & $2^{\text {nd }}$ & $00(0.00)$ & $12^{\text {th }}$ \\
\hline Commercial Transport (Taxi, Bus \& Napep) & $164(2.73)$ & $2^{\text {nd }}$ & $00(0.00)$ & $12^{\text {th }}$ \\
\hline Carpentry & $151(2.52)$ & $5^{\text {th }}$ & $00(0.00)$ & $12^{\text {th }}$ \\
\hline Fuelwood Business & $149(2.48)$ & $6^{\text {th }}$ & $382(6.37)$ & $2^{\text {nd }}$ \\
\hline Petty trading & $138(2.30)$ & $9^{\text {th }}$ & $81(1.35)$ & $11^{\text {th }}$ \\
\hline Laundry services & $130(2.16)$ & $10^{\text {th }}$ & $371(6.18)$ & $3^{\text {rd }}$ \\
\hline Repair of generators & $130(2.16)$ & $10^{\text {th }}$ & $00(0.00)$ & $12^{\text {th }}$ \\
\hline Sales of Charcoal & $129(2.15)$ & $12^{\text {th }}$ & $371(6.18)$ & $3^{\text {rd }}$ \\
\hline Sales and repair of handsets & $129(2.15))$ & $12^{\text {th }}$ & $00(0.00)$ & $12^{\text {th }}$ \\
\hline Dying of clothes & $129(2.15)$ & $12^{\text {th }}$ & $00(0.00)$ & $12^{\text {th }}$ \\
\hline Vending recharge cards & $120(2.00)$ & $17^{\text {th }}$ & $00(0.00)$ & $12^{\text {th }}$ \\
\hline Production of local drinks & $00(0.00)$ & $24^{\text {th }}$ & $359(5.98)$ & $5^{\text {th }}$ \\
\hline Hair entwining & $00(0.00)$ & $24^{\text {th }}$ & $261(4.35)$ & $6^{\text {th }}$ \\
\hline House help/babysitters & $00(0.00)$ & $24^{\text {th }}$ & $196(3.27)$ & $7^{\text {th }}$ \\
\hline Automobile mechanics & $143(2.38)$ & $7^{\text {th }}$ & $00(0.00)$ & $12^{\text {th }}$ \\
\hline Interlocks production/fixing & $143(2.38)$ & $7^{\text {th }}$ & $00(0.00)$ & $12^{\text {th }}$ \\
\hline Knitting/weaving & $00(0.00)$ & $24^{\text {th }}$ & $196(3.27)$ & $7^{\text {th }}$ \\
\hline Electrical installations & $164(2.73)$ & $2^{\text {nd }}$ & $00(0.00)$ & $12^{\text {th }}$ \\
\hline Shop attendants & $122(2.03)$ & $15^{\text {th }}$ & $00(0.00)$ & $12^{\text {th }}$ \\
\hline Bicycle repairs & $122(2.03)$ & $15^{\text {th }}$ & $00(0.00)$ & $12^{\text {th }}$ \\
\hline Bakery & $120(2.00)$ & $17^{\text {th }}$ & $00(0.00)$ & $12^{\text {th }}$ \\
\hline Cap making and washing & $116(1.93)$ & $19^{\text {th }}$ & $125(2.08)$ & $9^{\text {th }}$ \\
\hline Plumbing & $104(1.73)$ & $20^{\text {th }}$ & $00(0.00)$ & $12^{\text {th }}$ \\
\hline Petrol dispensing & $94(1.67)$ & $21^{\text {st }}$ & $107(1.78)$ & $10^{\text {th }}$ \\
\hline Vulcanizing & $72(1.20)$ & $22^{\text {nd }}$ & $00(0.00)$ & $12^{\text {th }}$ \\
\hline Iron bending & $72(1.20)$ & $22^{\text {nd }}$ & $00(0.00)$ & $12^{\text {th }}$ \\
\hline Total & $3,027(50.45)$ & & $2,973(49.55)$ & \\
\hline
\end{tabular}

Note: All responses in parentheses are percentages of the raw scores.

Table 2 revealed that tailoring/embroidery, car and carpet wash, commercial transport, carpentry, fuelwood business, petty trading, laundry services, repairs of generators, sales of charcoal and sales and repair of handsets are the ten top enterprises engaged in by IDPs in Borno State. Others include dying, knitting/weaving, automobile mechanics, interlocks production/fixing and electrical installations. Those ranked the least are shop attendance, bicycle repairs, bakery, cap making and washing, plumbing, petrol dispensing, vulcanizing and iron bending. Hypotheses 1: There is no significant gender difference on the socioeconomic impact of insurgency in Borno State, Nigeria. 
Table 3. t-test gender difference on the socio-economic impact of insurgency in Borno State

\begin{tabular}{cccccccc}
\hline Variable & $\mathbf{N}$ & $\mathbf{X}$ & SD & DF & t-cal. & t-crit. & Decision \\
\hline Male & 3027 & 2.83 & 1.24 & 193 & 1.43 & 1.79 & Accepted \\
Female & 2973 & 2.61 & 1.01 & & & & \\
\hline
\end{tabular}

Table 3, showed that the calculated t-value of 1.43 is less than t-critical of 1.79 . Thus, the null-hypothesis was upheld. Hypotheses 2: There is no significant gender difference on the enterprises engaged in by IDPs in Borno State, Nigeria

Table 4. t-test of gender difference on the enterprises engaged in by IDPs in Borno State

\begin{tabular}{cccccccc}
\hline Variable & $\mathbf{N}$ & $\mathbf{X}$ & SD & DF & t-cal. & t-crit. & Decision \\
\hline Male & 3027 & 2.30 & 2.21 & 193 & 1.62 & 1.27 & Rejected \\
Female & 2973 & 1.94 & 1.71 & & & & \\
\hline
\end{tabular}

Table 4 , indicated that the calculated t-value of 1.62 is greater than the t-critical of 1.27 . Thus, the null-hypothesis was rejected.

\subsection{Discussion}

Findings of the study revealed seven socio-economic impacts of Boko Haram insurgency and twenty-seven enterprises engaged in by the internally displaced persons in Borno State, Nigeria. Based on the findings of research question one which elicited information on the socio-economic impact of insurgency in Borno State, Nigeria. The data analyzed revealed that destructions of private and public structures, burnt vehicles and livestock killed/stolen comprised the major economic cost of insurgency in Borno State, Nigeria. Others are farm produce burnt/stolen, truncates movement of goods and services, shortens revenue generation and curtails cross-border trade. The finding of this study agrees with the studies of $[2,13,18]$ who reported that the insurgents inflict terrible damage to lives and livelihoods of people in Borno State and ruthlessly targeted communities that set up vigilante forces or helped the military, killing many, destroyed/burnt properties and resulted in an impromptu and exodus of others to flee.

On research question two which enthused information on the enterprises engaged in by IDPs in Borno State, Nigeria. The data analyzed revealed that tailoring/embroidery, car and carpet wash, commercial transport, carpentry, cap making and washing, plumbing, vulcanizing and iron bending among others. The findings of this study corroborates the studies of $[1,18]$ who expressed that internally displaced persons and other youths in Borno State seriously engaged in something worthwhile to do for a living such as various skills acquisition to hung on as a means of livelihood. Some of the entrepreneurships engaged by IDPs include tailoring, automobile mechanics, generator mechanics, fridge/refrigerator repairs, Napep assembling/coupling and repairs, car and carpet wash, laundry services, cap making and washing, computer services and plumbing among numerous others. On the null-hypothesis one tested at 0.05 alpha level which stated that is no significant gender difference on the socioeconomic impact of insurgency in Borno State, analysis of this study shows that significant difference does not exists. This is evident because the calculated t-value of 1.43 is less than tcritical of 1.79. Thus, the null-hypothesis was upheld. [14, 18, 19] affirms the findings of this study revealing that due to the menace of insurgency, sources of family income have been seriously devastated as farms, markets, shops, worship centers, private and public properties were destroyed and many residents that contribute commendably to the economic survival of the State were forced to migrate in exodus for their lives. On the null-hypothesis two tested at 
0.05 alpha level which stated that is no significant gender difference on the enterprises engaged in by IDPs in Borno State, analysis of this study shows that significant difference exists. This is evident because the calculated t-value of 1.62 is greater than the t-critical of 1.27. Thus, the null-hypothesis was overruled. [1, 14] affirms the findings of this study revealing that male and female enterprises has never been same in Borno State, Nigeria for reasons attributed to culture and gender stereotype.

\subsection{Implications for Counselling}

Based on findings of this study, unless the Federal and Borno State governments squarely addresses the problem of insurgency, poor governance, economic and other structural factors, the economy of the State would remain bankrupt. To prevent the current socio-economic impact of insurgency from prolonging, the federal government must match its military campaign against the insurgents with the momentum of a war. The Borno State government should as well have strong commitment to addressing the menace of insurgency to regain normalcy. Upholding law and equitable justice is the key to attaining normalcy in any society. Hence, there must be equitable distribution of wealth based on status and redirection of resources to priority areas.

The Borno State and local government areas should establish skills acquisition centers for the IDPs to acquire various trades as survival skills in addition to constructing counselling clinics across the State and engage certified counsellors to render counselling services at regular intervals in the areas of vocations, management of trauma and behaviour modification to promote value reorientation for a better tomorrow. The Banks (Bank of Industry, Merchant Banks, Agricultural Development Banks) and other financial institutions and Federal Ministry of Trade and Investment (FMTI) should assist the IDPs with soft loans under close monitoring/supervision as capital to commence or expand their trades with a view to revamping the economy and hung on for a living.

The counsellors, faith based clerics and educationists should in collaboration with Ministries of Education, National Orientation Agency, Civil Society Organizations and the Media organize Radio and Television programmes (talk shows, drama, phone-in calls, etc), public lectures, conferences and seminars involving IDPs, parents/guardians and the physically challenged (for the spirit of all-inclusiveness) to enlighten/educate them on the dangers of insurgency to the nation at large, Borno State in particular and its attendant multiplier economic consequences. The Borno State government should in collaboration with the security chiefs, para-militaries, Civilian Joint Task Force (CJTF) and other security outfits device ways and means of titivating/restoring peace and encourage farmers to go back to land, provide security for fishing activities and boost the grain markets to enhance cross-border trade with a view to guaranteeing domestic and household income generation.

\section{Conclusion}

Based on findings of this study, it is concluded that insurgency has bedeviled Borno State with huge socio-economic impact though not insurmountable. Some of the socio-economic impact of the insurgency identified include destructions of private and public structures, burnt vehicles, livestock killed/stolen, truncate movement of goods and services, abbreviates revenue generation and abridge cross-border trade. This has contributed negatively in loss of trillions of naira following forceful migration of people in exodus and consequently rendered 
the State bankrupt and crippled household income. The situation calls for serious counselling interventions involving the government at all levels, parents/guardians, security personnel and civil society organizations to device means and ways of restoring peace and boost economic activities of the State. Based on the findings, the following recommendations were proffered:

a) The Federal and Borno State governments should provide the military and other security personnel with adequate training, human and material resources to squarely fight insurgency with momentum of a war.

b) The Borno State government should through Ministries of Works and Reconstructions intensify efforts towards rebuilding skills acquisition centers, shops, markets and other personal assets that can propel socio-economic recovery of the State. Additionally, Banks and other financial institutions should assist the IDPs with soft loans.

\section{References}

[1] B. U. Ngohi, "All-inclusive education for skills acquisition: Implications for entrepreneurship development. ," Sokoto Educational Review Journal,, vol. 14(1), , pp. 93-101., (2019). .

[2] D. Mohammed and F. Ahmed, "The effect of insurgency on Borno state economy (2008-Oct. 2014)," Journal of Economics and Sustainable Development, vol. 6, no. 16, pp. 94-102, 2015.

[3] U. C. Chibuike and O. I. Eme, "Terrorism \& its Socio-Economic Effects in Nigeria," Journal of Contemporary Research in Social Sciences, vol. 1, pp. 97-113, 2019.

[4] D. H. Balami, I. Ogboru, and D. M. Talba, The cereal economy in Nigeria and the subregional dimension. Social Science Study Group (SSSG), Benue State University, Makurdi., 2011.

[5] C. E. Ugonna, L. C. Nwachukwu, C. C. Kalu, and I. A. Ugonna, "National Stability Through Youth Empowerment in Nigeria: Entrepreneurial Counselling Strategies," Online Journal of Arts, Management \& Social Sciences, vol. 2, no. 2, 2017.

[6] I. A. Joshua et al., "Social characteristics and risk factors for diseases among internally displaced persons: A study of stefano's foundation camp in Jos, Nigeria," Archives of Medicine and Surgery, vol. 1, no. 2, p. 42, 2016.

[7] O. N. Awojobi, "The socio-economic implications of Boko Haram insurgency in the north-east of Nigeria," International Journal of Innovation and Scientific Research, vol. 11, no. 1, pp. 144-150, 2014.

[8] R. E. Umezulike, "Youth Empowerment as a Veritable Instrument for Sustainable National Development: Implications for Counselling," South Eastern Journal of Research and Sustainable Development (SEJRSD), vol. 3, no. 1, pp. 14-35, 2020.

[9] D. Gollin, "Nobody's business but my own: Self-employment and small enterprise in economic development," Journal of Monetary Economics, vol. 55, no. 2, pp. 219-233, 2008.

[10] A. Adamu and M. Abdullahi, "The socio-economic implications of displacement in Nigeria: A survey on the internally displaced persons (IDPs) in the North-East," International Journal of Peace and Conflict Studies, vol. 6, no. 1, pp. 53-64, 2019.

[11] S. K. Mohanty, Fundamentals of entrepreneurship. PHI Learning Pvt. Ltd., 2005.

[12] M. Bintube, "Boko haram phenomenon: genesis and development in north eastern region Nigeria," International Journal of Sociology and Anthropology Research, vol. 1, no. 1, pp. 1-22, 2015. 
[13] U. I. Sani and A. H. Bello, "Socio-economic and Political Implications of Boko Haram Uprising on Nigeria," Ilorin Journal of Administration and Development, vol. 5, no. 1, pp. 36-45, 2019.

[14] A. B. Ribadu, "The Impact Of 'Boko Haram'On Trade In North-East Nigeria 20092015," Universiti Sains Malaysia, 2018.

[15] D. Pedersen, "Political violence, ethnic conflict, and contemporary wars: broad implications for health and social well-being," Social science \& medicine, vol. 55, no. 2, pp. 175-190, 2002.

[16] A. Kunle and A. Modupe, "Challenges of Diaspora's Contributions to Nigeria's National Development: The British/American Case Study," American Journal of Humanities and Social Sciences Research, vol. 3, no. 4, pp. 130-154, 2019.

[17] R. V. Krejcie and D. W. Morgan, "Determining sample size for research activities," Educational and psychological measurement, vol. 30, no. 3, pp. 607-610, 1970.

[18] C. K. Granville, "The Impact of Boko Haram Insurgency on the People of Borno State," 2020.

[19] L. E. Ebi, "The impact of the Boko Haram terrorist group on the socio-economic wellbeing and livelihood of the population in North-Eastern Nigeria," 2018. 